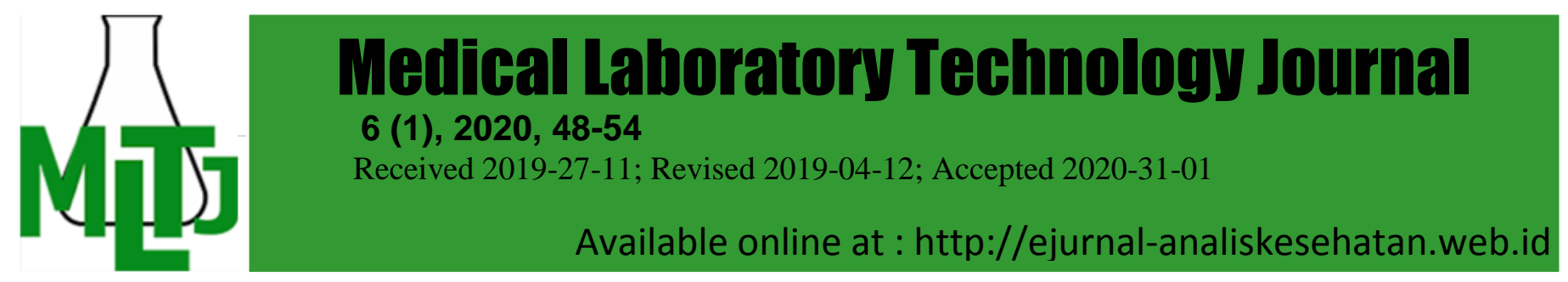

\title{
The Effect of Oral Contraceptive Pills on The Gene Mutation of Factor V Leiden among Sudanese Women
}

\section{Kawthar Abdelgaleil Mohammed Salih ${ }^{1}$, Hiba Abdelmalik ${ }^{1}$, Hiba Babiker ${ }^{1}$ ${ }^{*}$ Ahmed Bakheet Abd Alla ${ }^{2}$}

${ }^{1}$ Department of microbiology. ${ }^{2}$ Department of Parasitology and medical entomology College of medical laboratory science, Sudan University for Science and Technology, Khartoum, Sudan *Email: ahmed.hassanab@gmail.com

DOI: $10.31964 / \mathrm{mltj} . v 111.271$

\begin{abstract}
Oral contraceptive pills are problems for women, often have many effects, and may cause several diseases. The purpose of this research was to determine the impact of oral contraceptive pills on factor $V$ sufferers. This case-control study conducted in Khartoum Sudan during the period from April to November 2018. The study included 50 women who used oral contraceptive as a case and 50 women who did not use oral contraceptive pills as a control, all of whom were verbally informed of the study and approved for participation. The PCR do for each sample. The results obtained from cases show that the mean age is $30 \pm 5.5$ and divided into three groups less than 20 with a lower frequency of $4 \%(2 / 50),(20-35)$ with a higher incidence of $80 \%(40 / 50)$ and a higher rate of $16 \%(8 / 50)$ for more than 35 years. Most cases use the oral contraceptive pill for more than one year at a frequency of $60 \%(30 / 50)$ with a mean of $2 \pm 0.8$. The most frequent oral contraceptive pill use was levonorgestrel $88 \%$ (44/50), followed by desogestrel $12 \%(6 / 50)$. The study concludes that there is no significant difference in gene mutation between case and control. There was also an insignificant association between the mutation and demographic data.
\end{abstract}

Keywords: factor $\mathrm{V}$ Leiden; oral contraceptive; mutation; a polymerase chain reaction

\section{INTRODUCTION}

Oral contraceptives (OCs), also known as pills, are the most popular form of contraception (Dhont, 2010). The critical mechanism of action is ovulation suppression, and, besides, the oral contraceptive produces endometrium that is not receptive to ovum implantation and cervical mucus that has become dense and hostile to sperm transport(Hall et al., 2010).

Various types of oral contraceptives exist; combined oral contraceptives (COCs) containing estrogen and progestin (Kiley and Hammond, 2007), and Progestin-only contraception (POPs) containing progestin but no estrogen-containing this drug referred to as a mini-pill (Adamopoulou \& Vgenopoulou, 2015; Renner \& Edelman, 2016).

Oral contraceptive estrogen raises the number of clotting factors (II, VII, XII, VIII) in plasma (van Rooijen et al., 2002), Fibrinogen and thrombin activable fibrinolysis inhibitors by influencing gene transcription of different proteins (Hoppe, 2014). Estrogen crosses a cell membrane for a specific target tissue within a cytoplasm attached to a nuclear receptor (Bassett et al., 2003). Estrogen - an atomic receptor complex then moves to the nucleus where it identifies and binds to unique recognition sites that contribute to gene transcription by allowing RNA Polymerase II 
to transcribe proteins to that DNA region in this case, new proteins are the coagulation factors (Trenor et al., 2011; Aranda \& Pascual, 2001).

Factor $V$ is one of several substances that helps blood clots to increase blood clotting (Fogelson, \& Neeves, 2015), The clotting action of factor $V$ is regulated by another protein called the activated protein $C$ dose that does not function well with the abnormal factor V suffering protein factor V (Levi \& van der Poll, 2013) and increase the chance of developing deep vein blood clot (DVT) in the leg or lung (pulmonary embolus) (Gruber and Bull, 2012).

Oral contraceptives containing estrogen increase the plasma concentrations of clotting factors II, VII, X, XII, factor VIII, fibrinogen, and thrombin activatable fibrinolysis inhibitor (TAFI, but in a different manner (Afsar et al.,2008). Desogestrel containing oral contraceptives confers the most significant impact when compared to a second-generation oral contraceptive containing levonorgestrel these facts explain the increase in factor VII concentrations ( Vinogradova et al.,2014).

The decrease in factor $V$ may appear to be beneficial, necessary for the activation of prothrombin (II) to thrombin (Ila). Factor $\mathrm{V}$ works synergistically with protein $S$ to inhibit factor VIII, Estrogen, like many lipophilic hormones, affects the gene transcription of various proteins it increases plasma concentrations by crosses the cell membrane for a particular target tissue, which there are many that estrogen influence, and once inside the cytoplasm binds to nuclear receptors. The estrogen/nuclear receptor complex then travels into the nucleus where it recognizes and binds to specific recognition sites, called hormone response elements or, in this case, estrogen response elements. This binding then turns on gene transcription by allowing RNA polymerase II to transcribe the protein in that region of the DNA; these new proteins are the clotting factors and proteins. (Middeldorp et al .,2000).

Bergendal and his colleagues studied association venous thromboembolism with hormonal contraception and thrombophilic genotype. They found thrombophilic genotype such factor $V$ Leiden increased risk of venous thromboembolism in users of combined hormonal contraception (Bergendal et al., 2014). Also, pulmonary embolism and deep vein thrombosis related to oral contraceptive use and found all coagulation profile are standard. FV Leiden is negative. CT shows pulmonary embolism and discus it by venous thromboembolism arise from the acquired condition. Oral contraceptive is one of the purchased risk factors. (Kim and Kim, 2013)

Detection of factor $\mathrm{V}$ Leiden mutation by using a multiplex polymerase and found there no mutation in all subjects and risk factors are the most significant effect patients were oral contraceptive (Ibrahim et al., 2018).

Difference between the above studies and this study, here we try to detect mutation in factor $\mathrm{V}$ among women using oral contraceptives that may act as one of the possible risk factors that increase susceptibility to develop thrombosis among them. The purpose of this research was to determine the impact of oral contraceptive pills on factor $\mathrm{V}$ sufferers.

\section{MATERIALS AND METHOD}

This research was a prospective case-control study conducted at women use oral contraceptives during the period from April to November 2018. Fifty women use oral contraceptive (case group), and 50 women did not use any contraceptive (control group) enrolled in this study. As well as any women had coagulation problem, last time exposure to bleeding, thrombosis, or take vitamin effect on coagulation system were excluded from this study. 


\section{Sampling and data collection}

Three $\mathrm{ml}$ of venous blood was collected from each participant in the study using the disposable sterile syringe after disinfected the collection site with $70 \%$ alcohol then the blood was dispensed in a sterile EDTA blood container. Data were obtained by direct interviewing using a well-structured questionnaire.

\section{DNA extraction}

DNA was extracted from whole blood using Guanidine hydrochloride, $4 \mathrm{ml}$ of red blood lysis buffer (RCLB) added to each sample, then centrifuged for $5 \mathrm{~min}$ at $6000 \mathrm{rpm}$, this step repeated two times until a clear pellet of white blood cell have appeared, the supernatant was discard and(2 $\mathrm{ml}$ of white blood lysis buffer (WCLB), $1 \mathrm{ml}$ of guanidine hydrochloride, 300 of ammonium acetate $(\mathrm{NH} 4)$ and $10 \mu \mathrm{l}$ of proteinase $\mathrm{K}$ ) were added, then were incubated overnight at $37 \mathrm{C}^{\circ}$. After overnight incubation, the sample cooled at room temperature. Then $2 \mathrm{ml}$ of pre-chilled chloroform were added after that samples were centrifuge for $5 \mathrm{~min}$ at $6000 \mathrm{rpm}$, upper layer collected to new falcon tube contained $10 \mathrm{ml}$ of absolute cold ethanol, and then were incubated overnight at $-20 \mathrm{C}^{\circ}$.After overnight incubation, the sample was centrifugated for $10 \mathrm{~min}$ at $6000 \mathrm{rpm}$, the supernatant drained, pellet washed with $4 \mathrm{ml} 70 \%$ ethanol, then were centrifuged for $10 \mathrm{~min}$ at $6000 \mathrm{rpm}$, and supernatant poured off. Pellet was allowed to dry; then, the pellet was dissolved in $100 \mu$ lof double distilled water (DDW)and incubated at $4 \mathrm{C}^{\circ}$ until used (Chomczynski et al., 2006).

\section{PCR reaction}

Each Polymerase Chain Reaction PCR (Techne 312 thermocycler, England), reaction was performed using (Eppendorf master cycler) in a final volume of 20 containers (2.5Mm dNTPs, two target DNA.1(10pmol) of each primer $(\mathrm{C}, \mathrm{N}, \mathrm{M})$ and $2.5 \mathrm{U}(5 \mathrm{U} /)$ of Taq polymerase, followed by thermal cycler (Eppendorf master cycler) samples ARMS performed PCR reaction for Factor $V$ Leiden, the wild-type primer is 5, GGACAAATACCT GTATTCC3, the mutant primer is 5, GGACAAATAC CTGTATTCCTT3 and the standard primer is 5CTTTCA GGCAGGAACACC3. Thermal cycling conditions consisting of $5 \mathrm{~min}$ denaturation at $95 \mathrm{Co}$ followed by 35 denaturation cycles at $95 \mathrm{Co}$ for the $30 \mathrm{~s}$, annealing at $60^{\circ} \mathrm{C}$ for $30 \mathrm{~s}$, extension at $68 \mathrm{Co}$ for $60 \mathrm{~s}$, then final extension at $72 \mathrm{Co}$ for $5 \mathrm{~min}$, maintained at $4 \mathrm{Co}$ for use. The $\mathrm{PCR}$ reaction was treated with ethidium bromide on $2 \%$ agarose gel at $150 \mathrm{~V}$ for 45 minutes (Dajani et al., 2013).

\section{Ethical considerations}

Ethical approval obtained from the College of Medical Laboratory Committee, Sudan University of Science and Technology, Khartoum, Sudan Ethical approval No (MLS-IEC-02-17) Participants were verbally informed, in their simple language, about the research, its benefits, and the method of collecting the samples, and then their participation approval and publication of the data were obtained.

\section{Statistical analysis}

The statistical analysis of the result conducted using the Quantitative Package for Social Sciences (SPSS) version 16 for the interpretation of the results, a significant difference of less than 0.05 calculated using the Chi-square method.

\section{RESULTS AND DISCUSSION}

The study conducted to determine the subsequent effect of oral contraceptive on factor $\mathrm{V}$ gene includes 50 women using oral contraceptive age of the participating patient and a corresponding group of fifty healthy women who do not use oral contraceptive pills or other contraceptives. 
Both participants have no drug effect on hemostatic parameters and have no prior thrombosis or family history of bleeding or thrombosis. Participant's research classified in less than 20 (20-35) and more than 35 years by age in three groups. Based on the results, mean \pm StD $(30 \pm 5.5$ and $29 \pm 8.0)$ in the case and control, respectively, with insignificant $P . v a l u e=0.52$. The overall frequency in the case group showed that the higher rate $19(38.5 \%)$ were in women with more than three children (multi grand), while the lower frequency $3(6.5 \%)$ were in women with one child (primary).

In contrast, the higher rate of 19 (38.5\%) were in women with two (secondary) and three (multi) children for each among the control group (table 1). Women those used Levonorgestrel were more frequent 44 (88.5\%) than those used Dosogestrel 6 (12.5) (table 1). The age group of (20-35) years was the most frequent, while less than 20 years were the lowest constant (table. 1). The result of PCR showed that all samples give a reaction in wild type (normal); the mutant type was absent in all participants (figure 1).

Table1:Distribution of Demographic Data among Subjects

\begin{tabular}{lll}
\hline Variable & Case (\%) & Control (\%) \\
\hline Gravity & & \\
Primary (one child) & $3(6.5)$ & $4(8.5)$ \\
Secondary (two child) & $14(28.5)$ & $19(38.5)$ \\
Multi (three child) & $14(28.5)$ & $19(38.5)$ \\
Grand multi (more than three child) & $19(38.5)$ & \\
Type of oral contraceptive & & - \\
Levonorgestrel & $44(88.5)$ & - \\
Desogestrel & $6(12.5)$ & \\
Age group & & $6(12.5)$ \\
$>20$ & $2(4.5)$ & $31(62.5)$ \\
$20-35$ & $40(80.5)$ & $13(26.5)$ \\
$<35$ & $8(16.5)$ & \\
\hline
\end{tabular}

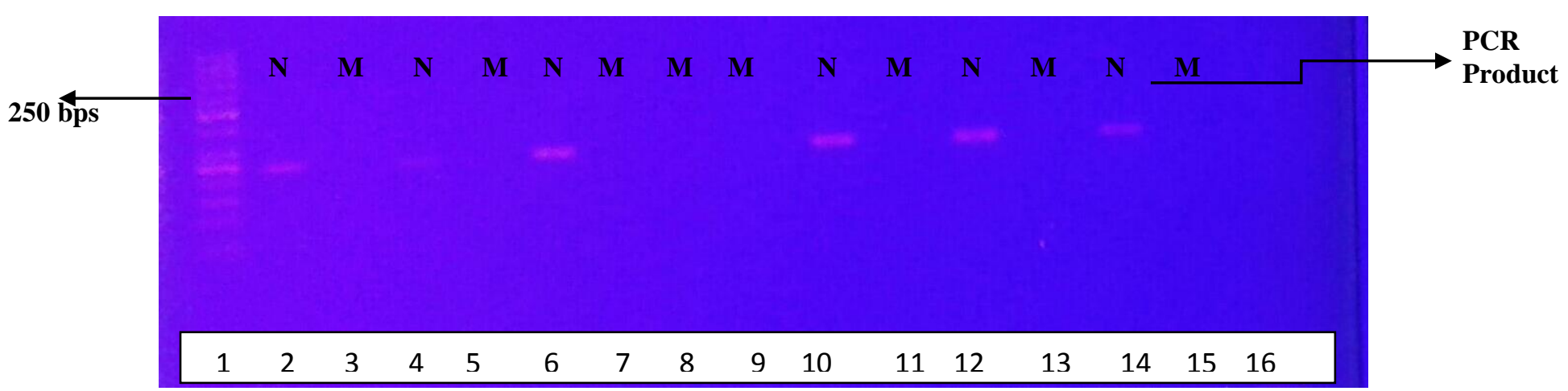

Figure 1: The PCR product for a participant, the lane one ladder $50 \mathrm{pb}, \mathrm{N}=$ normal (wild type), M=mutant, 2 - 16 PCR product.

The factor $V$ gene is located on chromosome $1 \mathrm{q} 23$ and contains 25 exons. The factor $\mathrm{V}$ gene defect occurs in exon ten where there is a G-A substitution at 
nucleotide 1691, this study showed that there no significant change on factor $\mathrm{V}$, this agreement with study of Ibrahim found there was no mutation in FV, but disagree in that most considerable affect patient in age 18-45 was oral contraceptive and in this study there no significant effect in period ( $P$.value $=0.5243)$ and there no correlation with mutation and other risk factors (age, gravity)[8]. Also agree with study done by Piparva, on deep vein thrombosis in women taking oral contraceptive and notice that woman taking oral combined contraceptive for 3-5 months, developed DVT thrombosis of left leg, hereditary and acquired causes of DVT excluded (there no mutation in factor $\mathrm{V}$ ) and believe that risk of blood clot due to dose of estrogen (Piparva et al., 2011).

In present study duration of use oral contraceptive found most cases use oral contraceptive for more than one year this mean use of oral contraceptive for long time act as protection by decrease risk of thrombosis this agrees with study of Martinelli that was divided case group into three (short less than year, long (1-5) year, very long more than five years) and found the risk of VTE in oral contraceptive user decrease over time (Martinelli et al., 2016)

In our study most of the cases use levonorgestrel that means this type of oral contraceptive not cause or have lower effect, this agree to with Vinogradova study risk of venous thromboembolism and exposure to combined oral contraceptive and found that type of progestogen hormone (drospirenone, desogestrel, gestodene, and cyproterone) were associated with increased risk of venous thromboembolism when compared to pill containing older progestogen (levonorgestrel and norethisterone) (Vinogradova et al., 2014).

Effect of oral contraceptive increased probability of VTE development depend on dose in medication and type of contraceptive used (Wolski, 2014). Limitation in this study summarized in difficulties to collect large sample size due to limited period of research and most of the women used more than one type of contraceptives irregular, that may interfere and made difficulties to collect it, as well as the high cost of PCR primers, acts as barriers made difficulties to use other advanced techniques

\section{CONCLUSION}

The study concludes that the oral contraceptive pill did not affect factor $\mathrm{V}$, and there no correlation between mutation and another risk factor (age, gravity), among Sudanese women. The risk-benefit calculations may alter completely for prophylactic interventions that carry no penalty, even if they are less active.

\section{ACKNOWLEDGMENT}

We thank sincerely our colleagues Dr.Abdallah Mosa and Dr.Hosham Noor Eldaim for their help and thank for staff in Research Laboratory of Medical Laboratory Science, Sudan University of Science and Technology, Finally, thanks to extended to all participants and volunteers in this study.

\section{CONFLICT OF INTEREST}

There were no conflicts of interest with related parties in this study.

\section{REFERENCE}

Adamopoulou, V., \& Vgeneopoulou. I. (2015). Hormonal Contraception: new insights on risk of venous thromboembolism. International Journal of Caring Scinces, 8(3), 843-852. 
Aranda, A., \& Pascual, A. (2001). Nuclear hormone receptors and gene expression. Physiological reviews, 8 (3), 1269-1304.

Bassett, J. D., Harvey, C. B., \& Williams, G. R. (2003). Mechanisms of thyroid hormone receptor-specific nuclear and extra nuclear actions. Molecular and cellular endocrinology, 213(1), 1-11.

Bergendal,A.,Person,I.,Odeberg,J.,Sundstrom,A.,Holmstrom,M.,Schulman,S.,Biorgel I,O and Kieler,H. (2014). Association of venous thromboembolism with hormonal contraception and thrombophilic genotype. Obstetrics and Gynecology, 124(3), $600-609$.

Chomczynski, P.,\& Sacchi, N. (2006). The single - step method of RNA isolation by acid guanidiniumthiocyanate- phenol- choloroform extraction: twentysomething years on. Nature Protocols, 1(2), 582-.2.

Dajani, R.,Arafat, A., Hakooz, N.,Albbadi, Z.,Yousef, A.,Elkateeb, M.,\& Quadan, F. (2013). Polymorphism in fator II and factor V thrombophilia gene among circssians in Jorda. Journal of Thrombosis and thrombolysis, 35(1), 83-89.

Dhont, M. (2010). History of oral contraception. The European Journal of Contraception \& Reproductive Health Care, 15(2), S12-8.

Fogelson, A. L., \& Neeves, K. B. (2015). Fluid mechanics of blood clot formation. Annual review of fluid mechanics, 47(1), 377-403.

Gruber, P.N., \& Bul,I M.T. (2012). Clinical medicine. Philadelphia; Elsevier, 947-97.

Hall, K.S., White, K.O ., Reame, N.,\& Westhoff, C. (2011). Studying the use of oral contraception: a rewiew of measurement approaches. Journal of women's health, 19(12), 2203-2210.

Hoppe, B. (2014). Fibrinogen and factor XIII at the intersection of coagulation, fibrinolysis and inflammation. Thrombosis and haemostasis, 112(10), 649-658.

Ibrahim, N.A.,Hassan., F. M.,Elagari, M.M., \& Abdalla, S.E. (2018). Risk factor for deep vein thrombosis of lower extremities in Sudanese women.Vasocular Health and Risk Managment, 14(20),157-164.

Kiley, J., \& Hammond, C. (2007). Combined oral contraceptives: a comprehensive review. Clinical obstetrics and gynecology, 50(4), 868-877.

Kim ,J.A., \& Kim, Y.S. (2013). Pulmonary embolism and deep vein thrombosis related to oral contraceptive use. Obstetrics and Gynecology Science, 56 (4),273-276.

Levi, M., \& van der Poll, T. (2013). Disseminated intravascular coagulation: a review for the internist. Internal and emergency medicine, 8(1), 23-32.

Martinelli, I., Maino, A., Abbattista, M., Bucciorrelli, P., Passamonti, S.M., Artori, A., Gianniello, F., \& Peyvandi F. (2016). Duration of oral contraceptive use and their venous thromboembolism a case-control study. Thrombosis Research, 141:153-7.

Middeldorp, S., Meijers, J.C., van den Ende, A.E., van Enk, A., Bouma, B.N., Tans, G., Rosing, J., Prins, M.H.,\& Büller, H.R. (2000). Effects on coagulation of levonorgestrel- and desogestrel-containing low dose oral contraceptives: a cross over-study. Thrombosis and Haemostasis, 84(1), 4-8.

Piparva, K.G.,\& Buch, J.G. (2011). Deep vein thrombosis in women taking oral combined contraceptive pills. Journal of pharmacology pharmacotherapeutics, 2(3), 185-186.

Renner, R. M., \& Edelman, A. (2016). Progestin-only oral contraceptives. In The Handbook of Contraception (pp. 79-86). Humana Press; Cham. 
Trenor, C., Chung, R., Michelson, A., Neufeld, E., Gordon,C., Laufer, M.,\& Emans, J. (2011). Hormonal contraception and Thrombotic risk: Amultidiscipllinary approach. Pediatrics ,127(2), 347-357.

Van Rooijen, M., von Schoultz, B., Silveira, A., Hamsten, A., \& Bremme, K. (2002). Different effects of oral contraceptives containing levonorgestrel or desogestrel on plasma lipoproteins and coagulation factor VII. American journal of obstetrics and gynecology, 186(1), 44-48.

Vinogradova, Y., Coupland, C.,\& Cox, J.H. (2014). Exposure to combined oral contraceptiveand risk of venous thromboembolism: aprotoocol for nested case -control studies using the $Q$ research and CPRD data base. British Medical Journal, 4:17.

Wolski, H. (2014). Select aspect of oral contraception side effects. National Center for Bio technology information, 85(12), 944-9. 